\title{
Histopathology
}

\section{Clinical significance and prognostic value of Chromatin Assembly Factor-1 overexpression in human solid tumors}

\begin{tabular}{|r|l|}
\hline Journal: & Histopathology \\
\hline Manuscript ID: & HISTOP-11-09-0664 \\
\hline Manuscript Type: & Original Article \\
\hline Author: & 30 -Nov-2009 \\
\hline Complete List of Authors: & $\begin{array}{l}\text { Polo, Sophie; Gurdon Institute } \\
\text { Theocharis, Stamatios; University of Athens, Medical School, } \\
\text { Department of ForensicMedicine and Toxicology } \\
\text { Grandin, Laure; Institut Curie, Department of Biostatistics } \\
\text { Gambotti, Laetitia; Institut Curie, Department of Biostatistics } \\
\text { Antoni, Guillemette; Institut Curie, Department of Biostatistics } \\
\text { Savignoni, Alexia; Institut Curie, Department of Biostatistics } \\
\text { Asselain, Bernard; Institut Curie, Department of Biostatistics } \\
\text { Patsouris, Efstratios; University of Athens, Medical School, First } \\
\text { Department of Pathology } \\
\text { Almouzni, Geneviève; Institut Curie, UMR218/CNRS }\end{array}$ \\
\hline Keywords: & \begin{tabular}{l} 
chromatin assembly, carcinoma, marker, prognosis, proliferation \\
\hline
\end{tabular} \\
\hline
\end{tabular}

\section{今 ScholarONE \\ Manuscript Central}




\section{Clinical significance and prognostic value of Chromatin Assembly Factor-1 overexpression in human solid tumors}

Sophie E. Polo ${ }^{1,5} \#$, Stamatios E. Theocharis ${ }^{3} \#$, Laure Grandin ${ }^{2}$, Laetitia Gambotti ${ }^{2}$, Guillemette Antoni 2,6, Alexia Savignoni 2, Bernard Asselain 2, Efstratios Patsouris ${ }^{4}$, Geneviève Almouzni ${ }^{1}$

${ }^{1}$ UMR218 Curie/CNRS; ${ }^{2}$ Department of Biostatistics, Institut Curie, Paris, France

${ }^{3}$ Department of Forensic Medicine and Toxicology; ${ }^{4}$ First Department of Pathology, Medical School, University of Athens, Athens, Greece

${ }^{5}$ Present address: Wellcome Trust/Cancer Research UK Gurdon Institute, Cambridge, UK

${ }^{6}$ Present address: INSERM, UMRS937, Paris, France

\# These authors equally contributed to this work

Address for correspondence: Dr G. Almouzni, UMR218 CNRS/Institut Curie, 26, rue d’Ulm, 75248 Paris cedex 5, France. Phone: +33 1562467 01; Fax: +33 1463330 16; E-mail : genevieve.almouzni@curie.fr.

Running title: CAF-1 prognostic marker in solid tumors

Keywords: chromatin assembly, carcinoma, marker, prognosis, proliferation. 


\begin{abstract}
Aims: The chromatin assembly factor CAF-1, whose function is critical for maintaining chromatin stability during DNA replication and repair, has been identified as a proliferation marker in breast cancer. Here, we investigate the interest of CAF-1 as a proliferation marker in a wide spectrum of solid tumors, and assess its potential value in predicting clinical outcome.

Methods and Results: Using immunocytochemistry on paraffin-embedded tissue sections, we compare CAF-1 labeling index with known proliferation markers Ki-67 and MCMs, and we analyze its association with clinicopathological data and patients' outcome. CAF-1 expression shows a strong positive correlation with $\mathrm{Ki}-67$, routinely used to detect proliferating cells, while it generally displays weaker correlations with MCM markers, known to label cells with replicative potential. CAF-1 expression is significantly associated with histological grade in breast, cervical, endometrial and renal cell carcinomas, and with disease stage in endometrial and renal carcinomas. Furthermore, high expression of CAF-1 is an independent predictor of adverse clinical outcome in renal, endometrial and cervical carcinomas.

Conclusions: These data demonstrate that CAF-1 is a proliferation marker in various malignant tumors with prognostic value in renal, endometrial and cervical carcinomas, which supports the relevance of CAF-1 as a clinical marker to monitor cancer progression.
\end{abstract}




\section{Introduction}

Cancer is a major cause of death in developed countries ${ }^{1}$. Early tumor detection as well as appropriate therapeutic decisions based on predicted clinical outcome and response to treatment are of key importance to treat cancer patients. Prediction of clinical outcome is generally based on the anatomical extent of disease (stage) and the degree of tumor differentiation (grade). In addition, molecular biomarkers ${ }^{2}$ including proliferation markers ${ }^{3}$ can be used for cancer diagnosis and prognosis. A common feature of cancer pathogenesis is indeed uncontrolled and rapid cell proliferation ${ }^{4}$. Accordingly, genes regulating cell proliferation have been observed to be overexpressed in the vast majority of tumor cells ${ }^{3}$.

Not only genetic alterations but also abnormalities at the chromatin level can contribute to the aberrant pattern of gene expression that promotes proliferation of cancer cells $^{5-7}$. Chromatin abnormalities have even been proposed to be an early and seminal event for cancer progression ${ }^{8}$, and anti-cancer treatments targeting chromatin components are in development ${ }^{9}$. While active research is aimed at a better understanding of distinct chromatin defects during tumoral progression, Chromatin alterations are certainly considered as valuable markers of malignant transformation ${ }^{10}{ }^{11}$, which may also provide prognostic information (reviewed in ${ }^{12}$ ).

The structural organization of DNA with histone proteins into chromatin ${ }^{13}$ is indeed of key importance for the regulation of gene expression, and maintenance of such an organization is thus crucial to preserve genome integrity and cellular identity ${ }^{14}$. Chromatin assembly ${ }^{15}$ involves specific factors called histone chaperones that escort histone proteins up to their deposition onto DNA ${ }^{16,17}$. Both during replication ${ }^{18}$ and repair events ${ }^{19}$, chromatin assembly is coupled to DNA synthesis. The only chaperone know so far that is able to promote this activity is called CAF-1 (Chromatin Assembly Factor-1), a trimeric nuclear 
complex ${ }^{20}$, made of p150, p60 ${ }^{21}$ and p48 subunits ${ }^{22}$ in human cells. Recent studies have highlighted CAF-1 intimate relationship with cell proliferation. In particular, CAF-1 expression is massively downregulated in quiescent cells ${ }^{23}$ and appears essential for human cell proliferation ${ }^{24-26}$. Furthermore, we previously validated the use of CAF-1 p60 expression as a proliferation marker of clinical value in breast cancer ${ }^{23}$. Here, we sought to extend these findings to a series of different human solid tumors and test the validity of CAF-1 p60 expression as a prognostic factor. 


\section{Materials and methods}

\section{Selection of cases}

Archival formalin-fixed, paraffin-embedded tissues and clinical material of common solid tumors including renal, colon, gastric, thyroid, pancreas, prostate, cervical, endometrial and breast cancer cases were provided by the First Department of Pathology of the University of Athens, which is a referral facility for the four University Hospitals in Athens, Greece. Selected patients correspond to consecutive cases of primary invasive tumors selected from an electronic medical record and diagnosed between 1994 and 2005, depending on the tumor type. All patients were examined routinely, according to institutional guidelines for each cancer type. The data reviewed, recorded in the hospital files, included baseline clinical and pathological data (available in Supporting information, Supplementary Table S1), the occurrence and the cause of death. Data were extracted in 2006. Immunohistochemical studies were performed on tissues obtained at surgery for cancer diagnosis. None of the patients had received either chemotherapy or radiotherapy before surgery. Patients received appropriate treatment afterwards, following standard procedures based on disease stage. Each patient had given informed consent and the study was approved by the ethical committee of the Medical School of University of Athens.

\section{Immunohistochemical staining}

Immunostainings for p60, Ki-67 and MCMs were performed on formalin-fixed paraffin embedded tissue sections $(4 \mu \mathrm{m})$ as previously described ${ }^{23}$ using the corresponding antibodies: CAF-1 p60 (mAb8133, Abcam), Ki-67 (MIB1, DAKO) and MCM proteins (MCM-2: MCA1859; MCM-5:MCA1860, Serotec).

\section{Statistical analyses}


The percentages of positively stained cells in immunocytochemistry experiments (labeling indexes) were obtained by scoring at least 1000 cells in each case by two independent observers, and the mean values were used for the following statistical analyses (S-Plus 2000 software, MathSoft Inc.). Correlations between continuous variables were studied using Spearman's rank correlation test. For multiple group comparisons of continuous variables the non parametric Kruskal-Wallis test was employed. Comparisons of labeling indexes obtained with two different markers between paired samples were performed by the non parametric Wilcoxon's signed-rank test. Statistical significance was taken as $\mathrm{p}<0.05$. Survival was assessed through medical records and defined as cause-specific survival, calculated from the date of surgical excision of the primary tumor to the date of death due to cancer or last followup. Survival data were systematically collected on the date of data extraction by telephone call to the patient. One case was censored because mortality was due an accident. Losses-tofollow-up were limited to an acceptable percentage of cases except in cervical cancer, where we verified that it did not bias the analysis since baseline characteristics of patients with or without survival data were not statistically different (Table S1). Survival curves were derived from Kaplan-Meier estimates. The association of CAF-1 p60 expression with clinical outcome was determined by univariate and multivariate Cox regression models with forward stepwise inclusion of factors and an inclusion criterion of $\mathrm{p}<0.20$. CAF-1 p60 expression was introduced as continous variable and as categorical variable in the models. Categorical variable was obtained by performing a median split of distribution. Due to the strong correlation between CAF-1 p60 and Ki-67, the latter was excluded from multivariate analyses. 


\section{Results}

\section{CAF-1 is a proliferation marker in various human carcinomas}

In order to test the validity of CAF-1 expression as a proliferation marker in solid tumors, we performed immunohistochemical detection of CAF-1 p60 on a series of paraffinembedded tissue sections including breast $(n=79)$, cervical $(n=64)$, endometrial $(n=62)$, renal $(n=55)$, prostate $(n=43)$, gastric $(n=64)$, colon $(n=108)$, pancreatic $(n=47)$ and thyroid $(n=52)$ carcinoma cases (Figure 1A). In each cancer type, we tested the correlation of CAF-1 p60 expression with the expression of the known marker of proliferation Ki-67 ${ }^{27}$. We also analyzed the association of CAF-1 expression with clinicopathological variables important for patients ${ }^{\prime}$ care and their final outcome (listed in Supporting information, Supplementary Table S1), in particular stage and grade.

Strong positive correlations were observed between CAF-1 p60 and Ki-67 labeling indexes in all tumors examined (from $\mathrm{r}=0.80$ in cervical cancer to $\mathrm{r}=0.99$ in pancreatic cancer, Figure 1B), demonstrating that CAF-1 is a proliferation marker of general value in human carcinomas. A consistently weaker correlation, although still significant, was observed with MCM proliferation markers ${ }^{28-30}$ as exemplified in gastric cancer (Figure 2A). Interestingly, MCM markers also commonly display significantly higher labeling indexes than CAF-1 p60 $(\mathrm{p}<0.001$ in colon, gastric and thyroid cancer, Figure 2B) while the fraction of cells detected with CAF-1 p60 and Ki-67 is comparable (based on Wilcoxon's signed-ranked test, data not shown).

Furthermore, CAF-1 p60 expression was significantly associated with histological grade in breast, cervical, endometrial and renal cell carcinoma $(p=0.016, p=0.037, p=0.0006$, $\mathrm{p}=0.0006$, respectively), and with disease stage in endometrial and renal cell carcinoma 
( $\mathrm{p}=0.012$ and $\mathrm{p}=0.015$, respectively). No significant associations with any other clinicopathological data examined were noted in our study.

Taken together, these data demonstrate that CAF-1 is a proliferation marker of clinical significance in a series of human solid tumors.

\section{CAF-1 expression is associated with adverse clinical outcome in a subset of tumor types}

The significant association of CAF-1 p60 expression with tumor stage and grade at least in a subset of tumor types prompted us to analyse the potential prognostic value of CAF1 marker. We therefore examined the association between CAF-1 p60 expression and causespecific patient survival by Kaplan-Meier analysis and Cox regression models on a series of patients with median follow-up ranging from 8 months for pancreatic cancer to 81 months for cervical cancer (Supporting information, Supplementary Table S1). Interestingly, CAF-1 p60 expression stood out as an independent predictor of survival in renal, endometrial and cervical cancers (Table 1, Figure 3). High levels of CAF-1 p60 immunostaining were indeed associated with poor clinical outcome in these cancer types (hazard ratio for death, 4.4, 5.5 and 3.3, with $\mathrm{p}=0.006,0.03$ and 0.04 for renal, endometrial and cervical tumors, respectively), based on multivariate Cox regression analyses (Table 1, Figure 3). The most significant differences were observed in renal cancer with 16 deaths in 22 patients with high p60 staining (median survival 8 months, range 2-66 months) compared with 7 deaths in 29 patients with low p60 staining (median survival 17 months, range 3-144 months). Our analyses did not show any significant prognostic value of CAF-1 detection in colon $(\mathrm{p}=0.64)$, gastric $(\mathrm{p}=0.43)$ and pancreatic $(\mathrm{p}=0.23)$ cancer. Univariate Cox regression analyses showed similar trends with CAF-1 p60 expression introduced as continous variable in the models 
(data not shown). Longer follow-up of patients will be required to examine CAF-1 prognostic value in slowly progressing breast, prostate and thyroid cancers.

Taken together, our data highlight the tight association of CAF-1 p60 expression with the proliferative state of the cells in various human solid tumors, validating its use as a general proliferation marker. Additionally, CAF-1 p60 level proved of prognostic significance in a subset of tumor types, namely renal, cervical and endometrial. These new data extend the clinical value of CAF-1 to assess cancer progression. 


\section{Discussion}

In this study, we have shown that the expression of the chromatin assembly factor CAF-1 is a clinically relevant indicator of cell proliferation in human carcinomas, thus confirming and extending our previous findings in breast cancer cases ${ }^{23}$. This property most likely relates to CAF-1 function coupled to DNA replication. Given the additional role of CAF-1 in chromatin assembly coupled to DNA repair ${ }^{19,31-35}$, it would also be worthwhile investigating its potential utility in monitoring/predicting tumor response to therapy. This requires a detailed analysis of CAF-1 expression levels in cells exposed to different sources of DNA damage, an issue that has begun to be considered only in one study ${ }^{36}$.

Our analyses also reveal that CAF-1 displays significant but notably weak correlations with MCM proliferation markers, which generally label a larger proportion of cells, suggesting that they detect distinct cell populations. This is consistent with the idea that MCMs mark cells with replicative potential in addition to actively proliferating cells ${ }^{37}$ while CAF-1 only labels the latter. A combination of both MCM and CAF-1 markers would thus be most useful to consider in difficult cases since MCM markers seem more sensitive and CAF-1 more discriminative.

In addition to its clinical utility for refining cancer diagnosis, CAF-1 marker also displays prognostic value, at least in a subset of the tumor types analysed (in particular in renal carcinomas), which can be useful for guiding therapeutic decisions. Interestingly, CAF1 p60 was also recently put forward as a marker of prognostic value in prostate cancer and squamous cell carcinoma of the tongue ${ }^{38,39}$, which further expands the list of human carcinomas in which high CAF-1 p60 expression is associated with adverse clinical outcome. 
Elucidation of the biological role of CAF-1 in cell proliferation and tumorigenesis is also of major interest. In particular, whether CAF-1 overexpression has oncogenic potential, as recently described for replication licensing factors ${ }^{40}$, remains to be examined. Furthermore, assessment of CAF-1 expression in early pre-cancerous lesions would also help clarifying when CAF-1 overexpression occurs in the course of cancer development.

Our results also need to be considered in light of the emerging concept of cancer stem cells $^{41}$, which refers to a small subpopulation of tumor cells that is required for tumor growth and therefore constitutes the main target of anti-cancer therapies. It would be interesting to compare CAF-1 expression in cancer stem cells relative to other cells within the tumor to determine if this marker is also associated with the cancer stem cell phenotype and if it could contribute to more sensitive detection methods for cancer stem cells. Another population of cells in which assesment of CAF-1 expression would be informative is stromal fibroblasts of the tumor microenvironment, which are known to potentiate tumor development ${ }^{42}$. These cells have indeed been reported to differ from their normal counterparts in terms of proliferation/migration capacities, which relates to differences in gene expression arising from chromatin changes rather than genetic alterations ${ }^{43-45}$

Finally, in light of recent genome-wide analyses of chromatin marks that identify specific alterations in human cancer cells (reviewed in ${ }^{46}$ ), our study underlines that a better understanding of chromatin-related events associated with tumorigenesis can prove useful for cancer diagnosis and prognosis. 


\section{Acknowledgements}

This work was supported by la Ligue Nationale contre le Cancer (Equipe labellisée la Ligue), ACI-2007-Cancéropôle IdF 'Breast Cancer and Epigenetics', the European Commission Network of Excellence Epigenome (LSHG-CT-2004-503433), contract RTN (HPRN-CT2002-00238), ACI-DRAB (no 04393) and a collaborative program 'Paramètres Epigénétiques' between the Curie Institute and the CEA. S. E. P. was supported by an ARC fellowship followed by a post-doctoral fellowship from Human Frontier Science Program Organization. We thank Faculty Members of the Medical School of the University of Athens (E. Agapitos, S. Tseleni, A. Kyroudi, G. Kouraklis, D. Mytropoulos) for samples and clinical data collection. 


\section{References}

1. Jemal A, Siegel R, Ward E, Hao Y, Xu J, Murray T, et al. Cancer statistics, 2008. CA Cancer J Clin 2008;58(2):71-96.

2. Sawyers CL. The cancer biomarker problem. Nature 2008;452(7187):548-52.

3. Whitfield ML, George LK, Grant GD, Perou CM. Common markers of proliferation. Nat Rev Cancer 2006;6(2):99-106.

4. Hanahan D, Weinberg RA. The hallmarks of cancer. Cell 2000;100(1):57-70.

5. Esteller M. Epigenetics provides a new generation of oncogenes and tumour-suppressor genes. Br J Cancer 2007;96 Suppl:R26-30.

6. Iacobuzio-Donahue CA. Epigenetic Changes in Cancer. Annu Rev Pathol 2008.

7. Jones PA, Baylin SB. The epigenomics of cancer. Cell 2007;128(4):683-92.

8. Baylin SB, Ohm JE. Epigenetic gene silencing in cancer - a mechanism for early oncogenic pathway addiction? Nat Rev Cancer 2006;6(2):107-16.

9. Yoo CB, Jones PA. Epigenetic therapy of cancer: past, present and future. Nat Rev Drug Discov 2006;5(1):37-50.

10. Fraga MF, Ballestar E, Villar-Garea A, Boix-Chornet M, Espada J, Schotta G, et al. Loss of acetylation at Lys16 and trimethylation at Lys20 of histone $\mathrm{H} 4$ is a common hallmark of human cancer. Nat Genet 2005;37(4):391-400.

11. Ozdag H, Teschendorff AE, Ahmed AA, Hyland SJ, Blenkiron C, Bobrow L, et al. Differential expression of selected histone modifier genes in human solid cancers. BMC Genomics 2006;7:90.

12. Kurdistani SK. Histone modifications as markers of cancer prognosis: a cellular view. $\mathrm{Br}$ J Cancer 2007;97(1):1-5.

13. Kornberg RD. Structure of chromatin. Annu Rev Biochem 1977;46:931-54. 
14. Groth A, Rocha W, Verreault A, Almouzni G. Chromatin challenges during DNA replication and repair. Cell 2007;128(4):721-33.

15. Polo SE, Almouzni G. Chromatin assembly: a basic recipe with various flavours. Curr Opin Genet Dev 2006;16(2):104-11.

16. Corpet A, Almouzni G. Making copies of chromatin: the challenge of nucleosomal organization and epigenetic information. Trends Cell Biol 2009;19(1):29-41.

17. De Koning L, Corpet A, Haber JE, Almouzni G. Histone chaperones: an escort network regulating histone traffic. Nat Struct Mol Biol 2007;14(11):997-1007.

18. Stillman B. Chromatin assembly during SV40 DNA replication in vitro. Cell 1986;45(4):555-65.

19. Gaillard PH, Martini EM, Kaufman PD, Stillman B, Moustacchi E, Almouzni G. Chromatin assembly coupled to DNA repair: a new role for chromatin assembly factor I. Cell 1996;86(6):887-96.

20. Smith S, Stillman B. Purification and characterization of CAF-I, a human cell factor required for chromatin assembly during DNA replication in vitro. Cell 1989;58(July 14):1525.

21. Kaufman PD, Kobayashi R, Kessler N, Stillman B. The p150 and p60 subunits of chromatin assembly factor I - a molecular link between newly synthesized histones and DNA replication. Cell 1995;81(7):1105-1114.

22. Verreault A, Kaufman PD, Kobayashi R, Stillman B. Nucleosome assembly by a complex of CAF-1 and acetylated histones H3/H4. Cell 1996;87(1):95-104.

23. Polo SE, Theocharis SE, Klijanienko J, Savignoni A, Asselain B, Vielh P, et al. Chromatin assembly factor-1, a marker of clinical value to distinguish quiescent from proliferating cells. Cancer Res 2004;64(7):2371-81.

24. Nabatiyan A, Krude T. Silencing of chromatin assembly factor 1 in human cells leads to cell death and loss of chromatin assembly during DNA synthesis. Mol Cell Biol 2004;24(7):2853-62. 
25. Ye X, Franco AA, Santos H, Nelson DM, Kaufman PD, Adams PD. Defective S phase chromatin assembly causes DNA damage, activation of the S phase checkpoint, and S phase arrest. Mol Cell 2003;11:341-351.

26. Hoek M, Stillman B. Chromatin assembly factor 1 is essential and couples chromatin assembly to DNA replication in vivo. Proc Natl Acad Sci U S A 2003;100:12183-12188.

27. Brown DC, Gatter KC. Monoclonal antibody Ki67: its use in histopathology. Histopathology 1990;17:489-503.

28. Tachibana KE, Gonzalez MA, Coleman N. Cell-cycle-dependent regulation of DNA replication and its relevance to cancer pathology. J Pathol 2005;205(2):123-9.

29. Freeman A, Morris LS, Mills AD, Stoeber K, Laskey RA, Williams GH, et al. Minichromosome Maintenance Proteins as Biological Markers of Dysplasia and Malignancy. Clin. Cancer Res. 1999;5:2121-2132.

30. Gonzalez MA, Tachibana KE, Laskey RA, Coleman N. Control of DNA replication and its potential clinical exploitation. Nat Rev Cancer 2005;5(2):135-41.

31. Green CM, Almouzni G. Local action of the chromatin assembly factor CAF-1 at sites of nucleotide excision repair in vivo. Embo J 2003;22(19):5163-74.

32. Martini E, Roche DM, Marheineke K, Verreault A, Almouzni G. Recruitment of phosphorylated chromatin assembly factor 1 to chromatin after UV irradiation of human cells. J Cell Biol 1998;143(3):563-75.

33. Polo SE, Roche D, Almouzni G. New Histone Incorporation Marks Sites of UV Repair in Human Cells. Cell 2006;127(3):481-93.

34. Lan L, Nakajima S, Oohata Y, Takao M, Okano S, Masutani M, et al. In situ analysis of repair processes for oxidative DNA damage in mammalian cells. Proc Natl Acad Sci U S A 2004;101(38):13738-43.

35. Okano S, Lan L, Caldecott KW, Mori T, Yasui A. Spatial and temporal cellular responses to single-strand breaks in human cells. Mol Cell Biol 2003;23(11):3974-81. 
36. Nabatiyan A, Szuts D, Krude T. Induction of CAF-1 expression in response to DNA strand breaks in quiescent human cells. Mol Cell Biol 2006;26(5):1839-49.

37. Stoeber K, Tlsty TD, Happerfield L, Thomas GA, Romanov S, Bobrow L, et al. DNA replication licensing and human cell proliferation. J Cell Sci 2001;114(Pt 11):2027-41.

38. Staibano S, Mascolo M, Mancini FP, Kisslinger A, Salvatore G, Di Benedetto M, et al. Overexpression of chromatin assembly factor-1 (CAF-1) p60 is predictive of adverse behaviour of prostatic cancer. Histopathology 2009.

39. Staibano S, Mignogna C, Lo Muzio L, Mascolo M, Salvatore G, Di Benedetto M, et al. Chromatin assembly factor-1 (CAF-1)-mediated regulation of cell proliferation and DNA repair: a link with the biological behaviour of squamous cell carcinoma of the tongue? Histopathology 2007;50(7):911-9.

40. Liontos M, Koutsami M, Sideridou M, Evangelou K, Kletsas D, Levy B, et al. Deregulated overexpression of hCdt1 and hCdc6 promotes malignant behavior. Cancer Res 2007;67(22):10899-909.

41. Ward RJ, Dirks PB. Cancer stem cells: at the headwaters of tumor development. Annu Rev Pathol 2007;2:175-89.

42. Bhowmick NA, Neilson EG, Moses HL. Stromal fibroblasts in cancer initiation and progression. Nature 2004;432(7015):332-7.

43. Qiu W, Hu M, Sridhar A, Opeskin K, Fox S, Shipitsin M, et al. No evidence of clonal somatic genetic alterations in cancer-associated fibroblasts from human breast and ovarian carcinomas. Nat Genet 2008;40(5):650-5.

44. Hu M, Yao J, Cai L, Bachman KE, van den Brule F, Velculescu V, et al. Distinct epigenetic changes in the stromal cells of breast cancers. Nat Genet 2005;37(8):899-905.

45. Allinen M, Beroukhim R, Cai L, Brennan C, Lahti-Domenici J, Huang H, et al. Molecular characterization of the tumor microenvironment in breast cancer. Cancer Cell 2004;6(1):17-32. 
46. Esteller M. Cancer epigenomics: DNA methylomes and histone-modification maps. Nat Rev Genet 2007;8(4):286-98. 


\section{Figure legends}

Figure 1 : Comparison between CAF-1 p60 and Ki-67 labeling indexes in various solid tumors.

A. Immunohistochemical staining for CAF-1 p60 and Ki-67 in breast and colon cancer specimens (original magnification X 200).

B. Correlations between CAF-1 p60 and Ki-67 labeling indexes in various human carcinomas. $\mathrm{r}=$ Spearman's rank correlation coefficient; linear regression line is represented; $\mathrm{N}=$ number of cases; All $\mathrm{p}$ values are $<10^{-4}$.

Figure 2: Comparison between CAF-1 p60 and MCMs labeling indexes.

A. Correlations between CAF-1 p60 and MCMs labeling indexes in gastric cancer. $\mathrm{r}=$ Spearman's rank correlation coefficient; linear regression line is represented; $N=$ Number of cases; All p values are $<10^{-4}$.

B. Boxplot representation of p60 and MCM5 labeling indexes in the indicated tumors. Box: $25^{\text {th }}-75^{\text {th }}$ percentile; horizontal line inside the box: median; dotted line: range; Diff.: difference between MCM5 and p60 labeling indexes presented as median (minimum-maximum); N: number of cases. Significance as determined by the Wilcoxon's signed-rank test is shown.

Figure 3 : Association of CAF-1 p60 expression level with clinical outcome.

Kaplan-Meier survival curves represent patients' cause-specific survival according to p60 levels. Patients are stratified in two groups based on the median of p60 labeling index as a cut-off (dashed line: high p60 labeling index; solid line: low p60 labeling index). Error bars represent $95 \%$ confidence intervals. $\mathrm{N}$ : number of cases. 

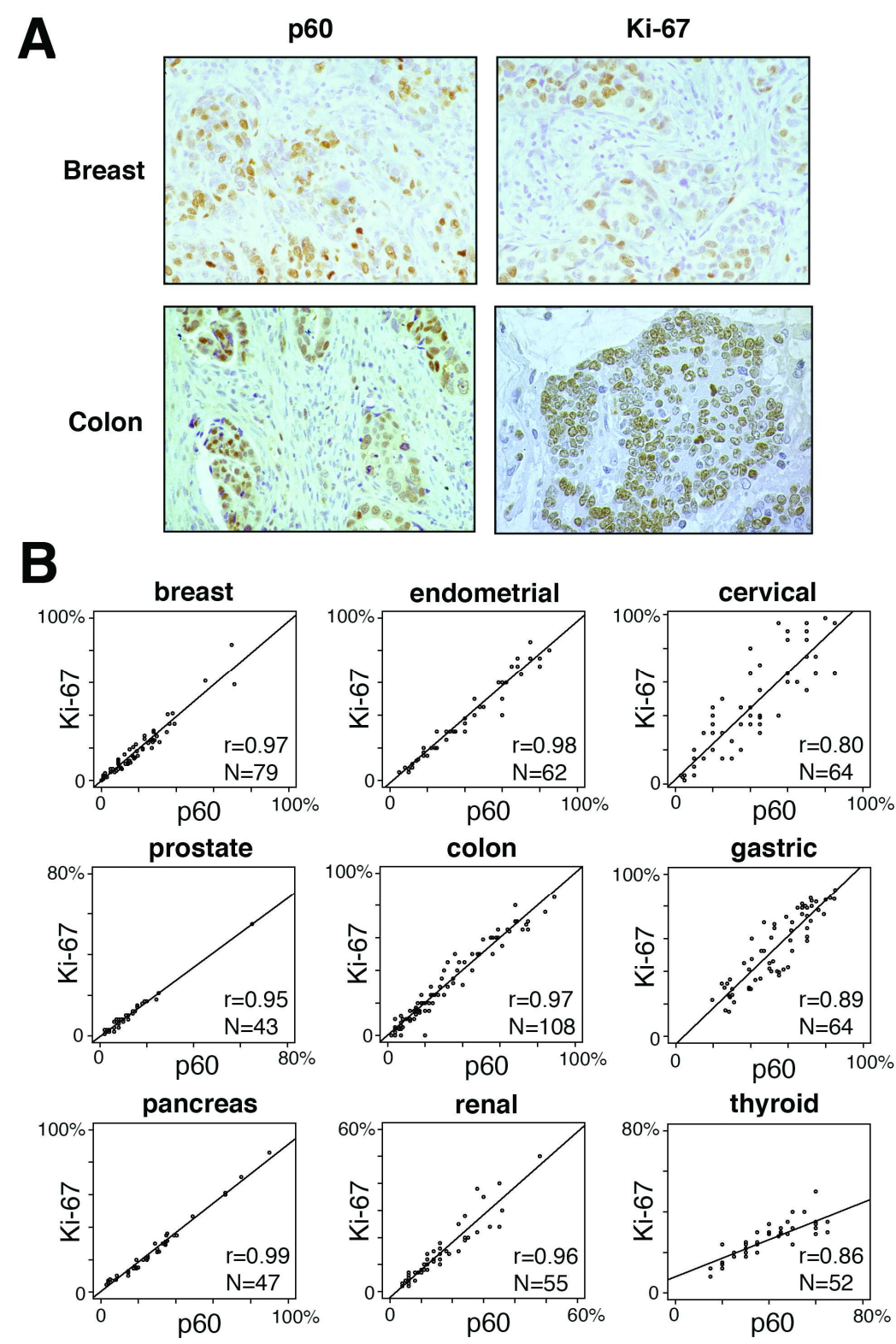

$170 \times 249 \mathrm{~mm}(300 \times 300 \mathrm{DPI})$ 


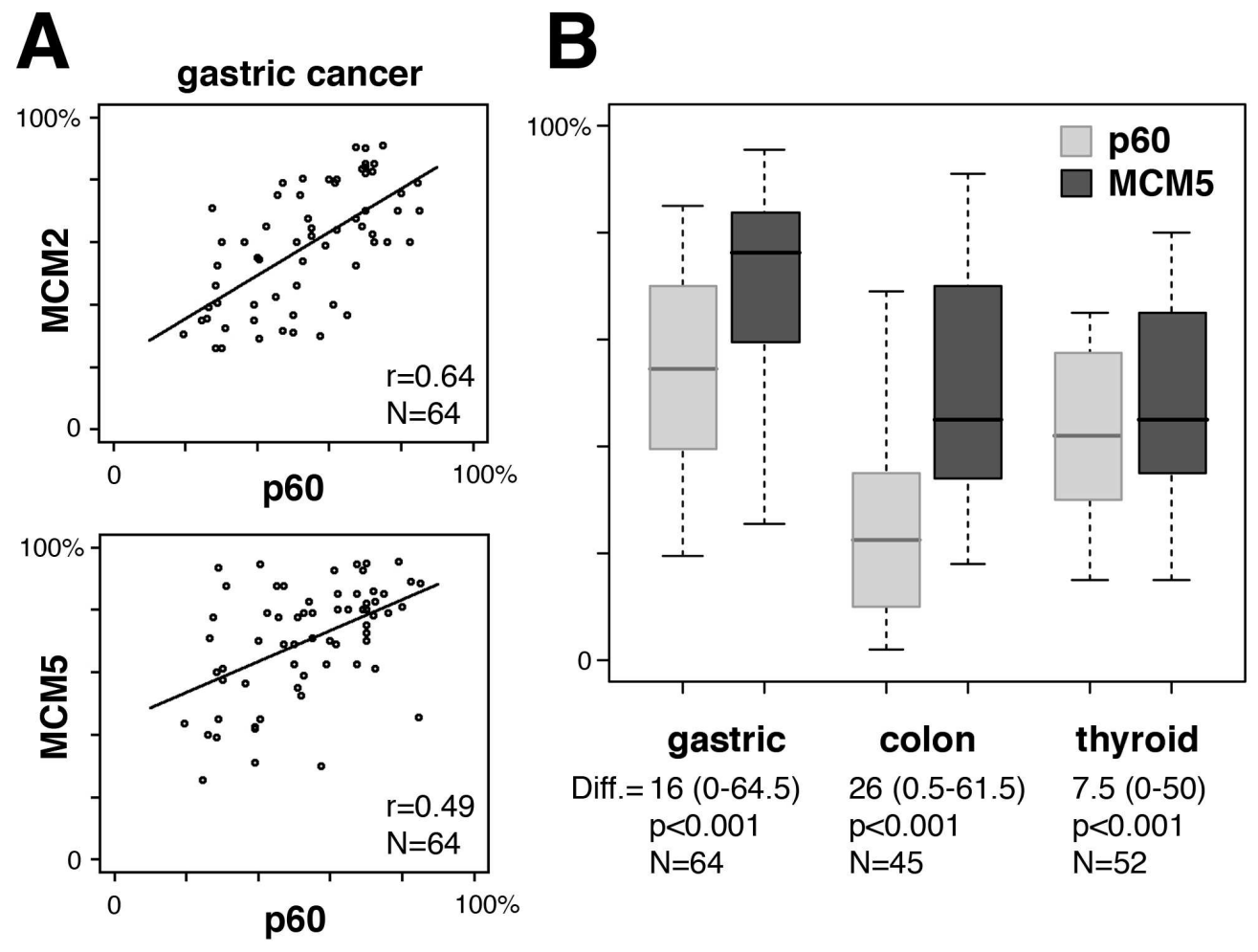

$169 \times 132 \mathrm{~mm}(300 \times 300 \mathrm{DPI})$ 

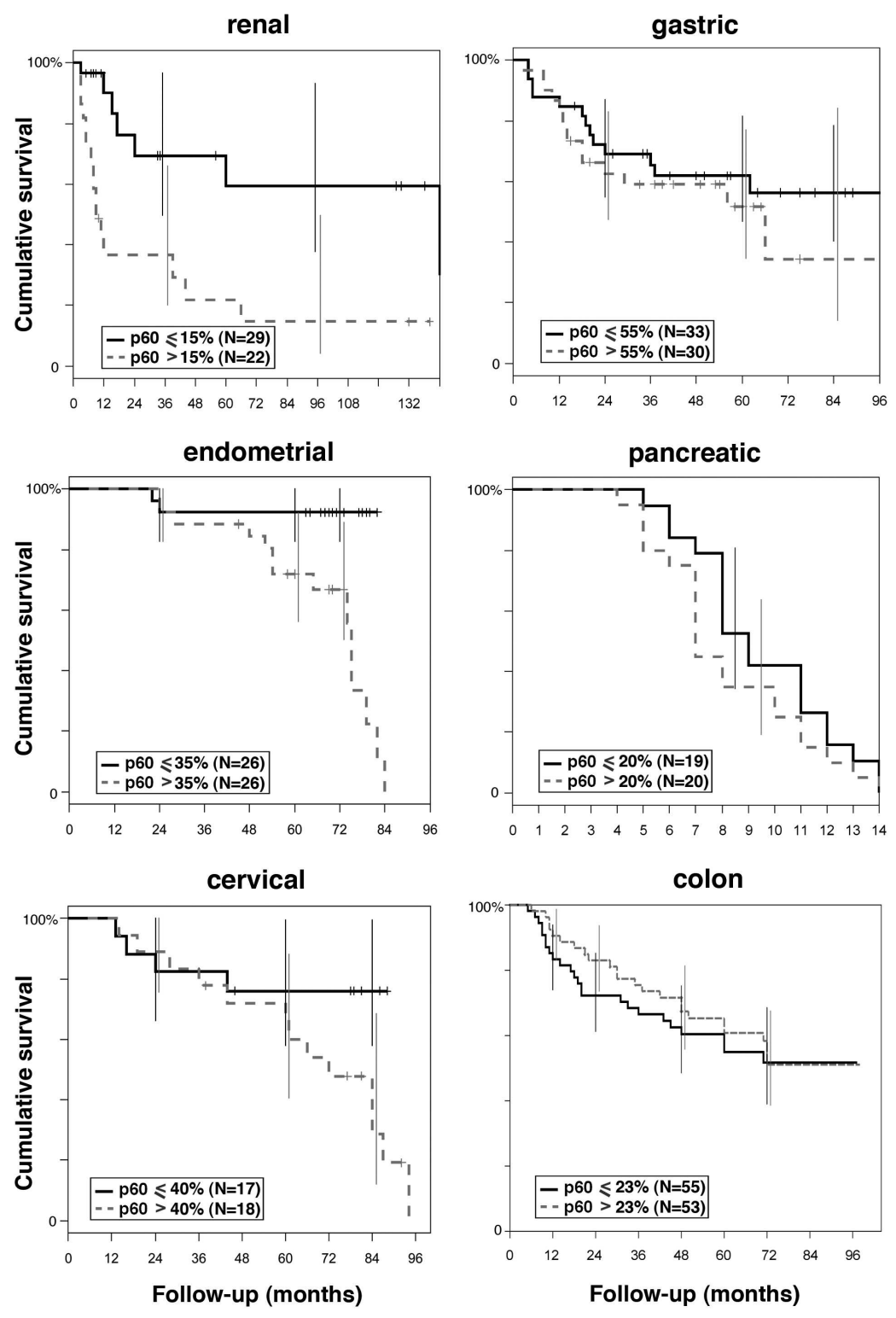

$168 \times 247 \mathrm{~mm}(300 \times 300$ DPI $)$ 
Table 1 : CAF-1 p60 prognostic value (prediction of cause-specific survival) determined by univariate and multivariate Cox regression models in the indicated tumors.

\begin{tabular}{|c|c|c|c|c|c|c|c|}
\hline \multirow[b]{2}{*}{ Cancer } & \multirow[b]{2}{*}{$\mathbf{N}$} & \multicolumn{3}{|c|}{ UNIVARIATE } & \multicolumn{3}{|c|}{ MULTIVARIATE } \\
\hline & & HR & 95\% C.I. & p & HR & 95\% C.I. & $\mathbf{p}$ \\
\hline Renal & 51 & & & & & & \\
\hline$p 60=<15 \%$ & 29 & 1 & & & 1 & & \\
\hline$p 60>15 \%$ & 22 & 4.9 & {$[1.9-12.6]$} & $<0.001$ & 4.4 & [1.4 - 14.0] & $0.006^{*}$ \\
\hline Endometrial & 52 & & & & & & \\
\hline$p 60=<35 \%$ & 26 & 1 & & & 1 & & \\
\hline p60>35\% & 26 & 8.7 & [1.9 - 38.7] & 0.005 & 5.2 & {$[1.1-25.6]$} & $0.03^{\dagger}$ \\
\hline Cervical & 35 & & & & & & \\
\hline$p 60=<40 \%$ & 17 & 1 & & & 1 & & \\
\hline$p 60>40 \%$ & 18 & 2.6 & {$[0.8-8.1]$} & $0.08^{\S}$ & 3.3 & {$[1.0-10.6]$} & $0.04^{\ddagger}$ \\
\hline Gastric & 63 & & & & - & - & NS \\
\hline$p 60=<55 \%$ & 33 & 1 & & & & & \\
\hline$p 60>55 \%$ & 30 & 1.4 & {$[0.6-2.9]$} & 0.43 & & & \\
\hline Pancreatic & 39 & & & & - & - & NS \\
\hline$p 60=<20 \%$ & 19 & 1 & & & & & \\
\hline$p 60>20 \%$ & 20 & 1.5 & [0.8 - 2.8] & 0.23 & & & \\
\hline Colon & 108 & & & & & - & NS \\
\hline$p 60=<23 \%$ & 55 & 1 & & & & & \\
\hline p60>23\% & 53 & 0.9 & {$[0.5-1.5]$} & 0.64 & & & \\
\hline
\end{tabular}

In addition of $\mathrm{p} 60$, forward stepwise inclusions were performed with:

* age (not included in the final model), TNM ( $\mathrm{p}=0.003)$ and Fuhrman grade $(\mathrm{p}=0.003)$

$\dagger$ histological grade (not included in the final model) and FIGO stage $(\mathrm{p}=0.005)$

$\ddagger$ histological grade and lymph node invasion (global p-value $=0.009$ )

$\S$ In the cervical cancer cases analysed in our study, squamous histological type that has good prognosis is more frequently, although not significantly, associated with high p60 values than adenocarcinoma type, an indicator of bad prognosis. This explains why p60 shows a 
significant association with clinical outcome in multivariate analysis only, while its effect is masked by histological type in univariate analysis.

\begin{tabular}{|c|c|c|c|c|c|c|c|}
\hline \multirow{2}{*}{$\begin{array}{l}\text { Renal cancer } \\
\text { variables }\end{array}$} & \multirow[b]{2}{*}{$\mathbf{N}$} & \multicolumn{3}{|c|}{ UNIVARIATE } & \multicolumn{3}{|c|}{ MULTIVARIATE } \\
\hline & & HR & 95\% C.I. & $\mathbf{p}$ & HR & 95\% C.I. & $p$ \\
\hline $\operatorname{sex}$ & & & & 0.96 & & & \\
\hline male & 34 & 1 & & & & & \\
\hline female & 17 & 1.0 & [0.4 - 2.5] & & & & \\
\hline age (years) & & & & 0.03 & & & \\
\hline$>60$ & 25 & 1 & & & & & \\
\hline$<=60$ & 26 & 0.4 & {$[0.1-0.9]$} & & & & \\
\hline TNM & & & & 0.001 & & & 0.003 \\
\hline T1N0, T2N0 & 22 & 1 & & & 1 & & \\
\hline $\mathrm{T} 2 \mathrm{~N}+$ & 2 & 12.1 & {$[1.9-75.8]$} & & 28.9 & [3.8 - 221] & \\
\hline T3NO & 18 & 2.8 & [ $0.8-10.5]$ & & 0.8 & {$[0.2-3.8]$} & \\
\hline $\mathrm{T} 3 \mathrm{~N}+$ & 3 & 12.6 & [ $2.4-65.7]$ & & 2.8 & {$[0.4-17.2]$} & \\
\hline T4N0, T4N+ & 6 & 12.5 & {$[3.0-51.7]$} & & 5.0 & [1.1 - 22.8] & \\
\hline grade & & & & $<0.001$ & & & 0.003 \\
\hline I, II & 24 & 1 & & & 1 & & \\
\hline III, IV & 26 & 4.8 & [ $1.8-13.2]$ & & 5.8 & [1.6 - 20.5] & \\
\hline p60 L.I. & & & & $<0.001$ & & & 0.006 \\
\hline$<=15$ & 29 & 1 & & & 1 & & \\
\hline >15 & 22 & 4.9 & {$[1.9-12.6]$} & & 4.4 & {$[1.4-14.0]$} & \\
\hline
\end{tabular}

Patients are stratified in two groups based on the median of p60 labeling index as a cut-off (also see Figure 3). N : number of cases ; HR : Hazard Ratio ; C.I. : Confidence Interval ; L.I. : Labeling Index ; NS : Not Significant. 
Table S1 : Clinico-pathological data.

Values are presented as median [minimum-maximum] for continuous variables and number of patients (N, \%) for categorical variables.

\begin{tabular}{|c|c|c|}
\hline BREAST & $\mathrm{N}=80$ & \\
\hline \multirow[t]{2}{*}{ Age (years) } & 56 & [22-88] \\
\hline & $\mathbf{N}$ & $\%$ \\
\hline Histological type & 80 & \\
\hline ductal & 55 & 69 \\
\hline lobular & 0 & 0 \\
\hline mixed & 3 & 4 \\
\hline fibroadenoma & 6 & 7 \\
\hline fibrocystic disease & 16 & 20 \\
\hline Histological grade & 57 & \\
\hline I & 7 & 12 \\
\hline II & 34 & 60 \\
\hline III & 16 & 28 \\
\hline $\mathbf{T}$ & 57 & \\
\hline T1 & 23 & 40 \\
\hline $\mathrm{T} 2$ & 26 & 46 \\
\hline T3, T4 & 8 & 14 \\
\hline $\mathbf{N}$ & 58 & \\
\hline No & 23 & 40 \\
\hline N1 & 25 & 43 \\
\hline N2 & 9 & 15 \\
\hline N3 & 1 & 2 \\
\hline M & 58 & \\
\hline Mo & 56 & 97 \\
\hline M1 & 2 & 3 \\
\hline
\end{tabular}

\begin{tabular}{lcc} 
ENDOMETRIAL & $\mathbf{N}=\mathbf{6 2}$ & \\
Follow-up (months) & 70 & {$[45-84]$} \\
Age (years) & 65 & {$[40-82]$} \\
\hline & $\mathbf{N}$ & $\%$ \\
\hline Histological type & $\mathbf{6 2}$ & \\
adenocarcinoma & 49 & 79 \\
squamous component & 13 & 21 \\
Histological grade & $\mathbf{6 0}$ & \\
well differentiated & 16 & 27 \\
moderately & 37 & 62 \\
poorly & 7 & 11 \\
FIGO stage & $\mathbf{6 2}$ & \\
1a & 5 & 8 \\
1b & 21 & 34 \\
1c & 26 & 42 \\
2a & 3 & 5 \\
2b & 2 & 3 \\
3a & 2 & 3 \\
4a & 3 & 5 \\
Status & $\mathbf{5 2}$ & \\
Dead & 16 & 31 \\
Alive & 36 & 69 \\
\hline
\end{tabular}

\begin{tabular}{|c|c|c|}
\hline \multirow[t]{2}{*}{$\begin{array}{l}\text { Follow-up (months) } \\
\text { Age }\left(\text { years) }{ }^{\star}(3)\right.\end{array}$} & $\begin{array}{c}81 \\
53.5\end{array}$ & $\begin{array}{l}{[36-94]} \\
{[30-91]}\end{array}$ \\
\hline & $\mathbf{N}$ & $\%$ \\
\hline Histological type* (1) & 64 & \\
\hline adenocarcinoma & 10 & 16 \\
\hline squamous & 46 & 72 \\
\hline mixed type & 8 & 12 \\
\hline Histological grade ${ }^{\star}(1)$ & 62 & \\
\hline well differentiated & 9 & 15 \\
\hline moderately & 43 & 69 \\
\hline poorly & 10 & 16 \\
\hline FIGO stage ${ }^{\star}(1)$ & 63 & \\
\hline $1 \mathrm{a}$ & 6 & 10 \\
\hline $1 b$ & 55 & 87 \\
\hline $2 a$ & 2 & 3 \\
\hline Lymph node invas. ${ }^{*}(1)$ & 64 & \\
\hline Yes & 9 & 14 \\
\hline No & 55 & 86 \\
\hline Lymphatics invas. ${ }^{*}(2)$ & 63 & \\
\hline Yes & 41 & 65 \\
\hline No & 22 & 35 \\
\hline Vessel invasion* (2) & 63 & \\
\hline Yes & 23 & 37 \\
\hline No & 40 & 63 \\
\hline Status & 35 & \\
\hline Dead & 17 & 49 \\
\hline Alive & 18 & 51 \\
\hline
\end{tabular}

${ }^{*}$ not statistically different between patients with or without follow-up data based on $p>0.05$ with:

(1) Fisher's exact test

(2) Pearson's Chi-Squared test

(3) Wilcoxon rank sum test
GASTRIC

$\mathrm{N}=64$

Follow-up (months) $57 \quad$ [15-126] Age (years)

\begin{tabular}{lcc} 
& N & $\%$ \\
\hline Sex & 64
\end{tabular}

Female

Male

$\begin{array}{ll}17 & 27\end{array}$

T

T1

T2

T3

T4

N

N2

Stage

$1 a$

$1 b$

2

$3 a$

4

Histological type

Intestina

Diffuse

Mixed

Histological grade

well differentiated

moderately

poorly

Status

Dead

Alive 


\begin{tabular}{|c|c|c|c|c|c|c|c|c|c|c|c|}
\hline PANCREAS & $\mathrm{N}=47$ & & COLON & $\mathrm{N}=108$ & & THYROID & $\mathrm{N}=52$ & & RENAL & $\mathrm{N}=55$ & \\
\hline Follow-up (months) & 8 & {$[4-14]$} & Follow-up (months) & 79 & {$[6-98]$} & Follow-up (months) & 48 & {$[4-48]$} & Follow-up (months) & 34 & {$[5-144]$} \\
\hline \multirow[t]{2}{*}{ Age (years) } & 67 & {$[46-84]$} & Age (years) & 70 & [34-94] & Age (years) & 46 & [14-78] & Age (years) & 60.5 & [33-80] \\
\hline & $\mathbf{N}$ & $\%$ & & $\mathbf{N}$ & $\%$ & & $\mathbf{N}$ & $\%$ & & $\mathbf{N}$ & $\%$ \\
\hline $\mathbf{T}$ & 47 & & Sex & 108 & & Sex & 52 & & Sex & 55 & \\
\hline T1 & 4 & 8 & Female & 44 & 41 & Female & 38 & 73 & Female & 17 & 31 \\
\hline T2 & 6 & 13 & Male & 64 & 59 & Male & 14 & 27 & Male & 38 & 69 \\
\hline T3 & 30 & 64 & Stage & 108 & & $\mathbf{T}$ & 50 & & TNM & 55 & \\
\hline T4 & 7 & 15 & A & 20 & 19 & $\mathrm{~T} 1$ & 5 & 10 & $\mathrm{~T} 1, \mathrm{~T} 2 \mathrm{~N} 0$ & 22 & 40 \\
\hline $\mathbf{N}$ & 47 & & B & 47 & 43 & $\mathrm{~T} 2$ & 23 & 46 & $\mathrm{~T} 2 \mathrm{~N}+$ & 2 & 4 \\
\hline No & 24 & 51 & C1 & 21 & 19 & T3 & 11 & 22 & T3NO & 21 & 38 \\
\hline N1 & 23 & 49 & $\mathrm{C} 2$ & 20 & 19 & $\mathrm{~T} 4$ & 11 & 22 & $\mathrm{~T} 3 \mathrm{~N}+$ & 3 & 5 \\
\hline M & 47 & & Grade & 104 & & $\mathbf{N}$ & 50 & & T4Nany & 7 & 13 \\
\hline M0 & 47 & 100 & 1 & 10 & 10 & No & 23 & 46 & Histological type & 51 & \\
\hline M1 & 0 & 0 & II & 79 & 76 & $\mathrm{~N} 1$ & 27 & 54 & clear cell & 38 & 74 \\
\hline Stage & 47 & & III & 15 & 14 & $\mathbf{M}$ & 50 & & papillary & 9 & 18 \\
\hline IA & 4 & 8.5 & Vessel invasion & 108 & & Mo & 47 & 94 & chromophobe & 3 & 6 \\
\hline IB & 4 & 8.5 & Yes & 67 & 62 & M1 & 3 & 6 & sarcomatoid & 1 & 2 \\
\hline$\| \mathrm{A}$ & 13 & 28 & No & 41 & 38 & Stage & 52 & & Fuhrman grade & 51 & \\
\hline IIB & 19 & 40 & Status & 108 & & 1 & 11 & 21 & 1 & 10 & 20 \\
\hline III & 7 & 15 & Dead & 48 & 44 & II & 15 & 29 & II & 14 & 28 \\
\hline IV & 0 & 0 & Alive & 60 & 56 & III & 21 & 40 & III & 17 & 34 \\
\hline Histological grade & 46 & & & & & IV & 5 & 10 & IV & 8 & 18 \\
\hline 1 & 7 & 15 & PROSTATE & $\mathrm{N}=43$ & & Histological type & 52 & & Status & 51 & \\
\hline II & 31 & 67.5 & & & & Myeloïd & 35 & 67 & Dead & 23 & 45 \\
\hline III & 8 & 17.5 & Age (years) & 69 & [52-79] & Huertle cell & 3 & 6 & Alive & 28 & 55 \\
\hline Status & 39 & & & $\mathbf{N}$ & $\%$ & Anaplastic & 2 & 4 & & & \\
\hline Dead & 39 & 100 & Gleason's score & 43 & & Papillary & 12 & 23 & & & \\
\hline \multirow[t]{10}{*}{ Alive } & 0 & 0 & 5 & 7 & 16 & Status & 52 & & & & \\
\hline & & & 6 & 6 & 14 & Dead & 6 & 12 & & & \\
\hline & & & 7 & 21 & 49 & Alive & 46 & 88 & & & \\
\hline & & & 8 & 5 & 12 & & & & & & \\
\hline & & & 9 & 4 & 9 & & & & & & \\
\hline & & & $\mathbf{T}$ & 43 & & & & & & & \\
\hline & & & 1 & 3 & 7 & & & & & & \\
\hline & & & 2 & 16 & 37 & & & & & & \\
\hline & & & 3 & 23 & 54 & & & & & & \\
\hline & & & 4 & 1 & 2 & & & & & & \\
\hline
\end{tabular}

